Prepared for the National Aeronautics and Space Administration

\title{
Geologic Map of Meridiani Planum, Mars
}

By Brian M. Hynek and Gaetano Di Achille

Pamphlet to accompany

Scientific Investigations Map 3356

Version 1.1, April 2017

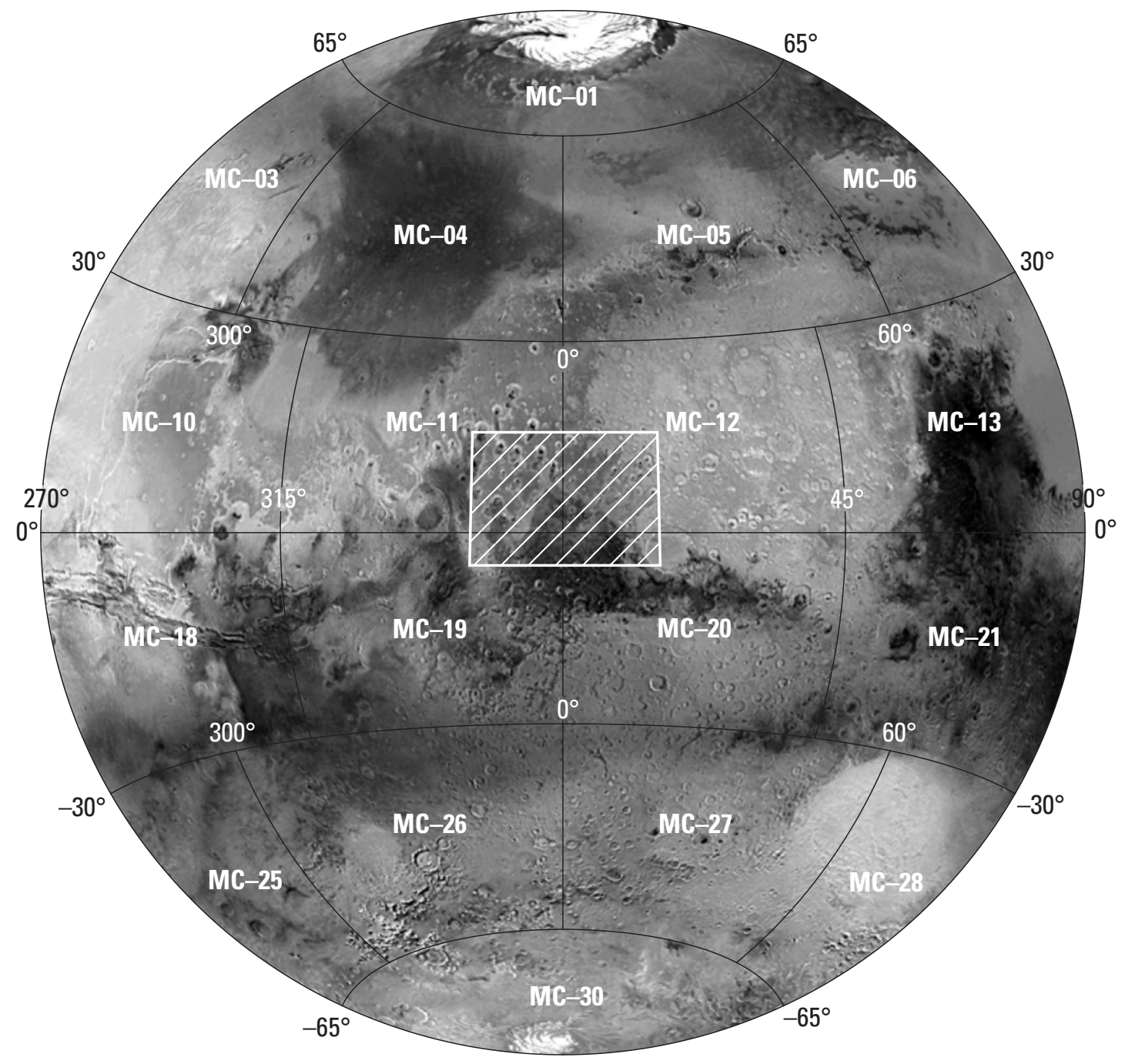

2017

U.S. Department of the Interior

U.S. Geological Survey 



\section{Contents}

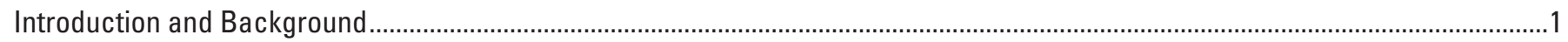

Data

Mapping Methods

Age Determinations

Geologic History

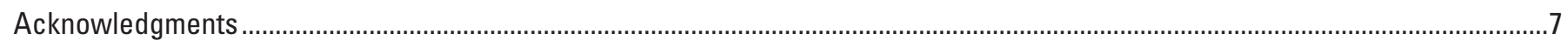

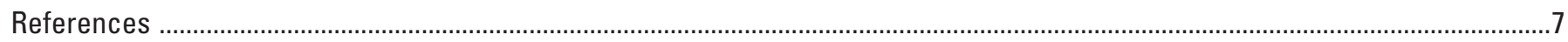

\section{Table}

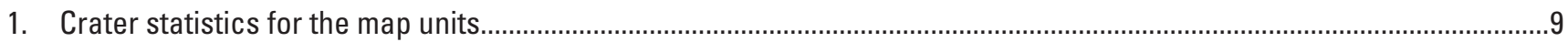





\section{Introduction and Background}

The Meridiani Planum region of Mars - originally named due to its proximity to the Martian prime meridiancontains a variety of geologic units, including those that are crater-related, that span the Early Noachian to Late Amazonian Epochs. Mars Global Surveyor (MGS) data indicate this area contains extensive layered deposits (for example, Hynek and others, 2002), some of which are rich in the mineral hematite (Christensen and others, 2001a). The National Aeronautics and Space Administration's (NASA) Mars Exploration Rover (MER) Opportunity landed in Meridiani Planum in early 2004 and, at the time of this writing, is still conducting operations. A variety of water-altered bedrock outcrops have been studied and contain indications of prolonged surface and near-surface fluid/rock interactions (for example, Squyres and others, 2004, 2009; Squyres and Knoll, 2005). The purpose of this study is to use the more recent orbiter data to place the rover's findings in a broader context by assessing the geologic and hydrologic histories of the region.

The map region extends from lat $-5^{\circ}$ to $15^{\circ} \mathrm{N}$. and from long $345^{\circ}$ to $15^{\circ} \mathrm{E}$. This area covers parts of the following 1:5,000,000 scale quadrangles (1) MC-11 (Oxia Palus), (2) MC-12 (Arabia), (3) MC-19 (Margaritifer Sinus), and (4) MC-20 (Sinus Sabaeus). The map region primarily contains Terra Arabia and Meridiani Planum and is bounded by Iani Chaos to the west, Margaritifer to the southwest, Noachis Terra to the south, and Terra Sabaea to the east. The regional slope trends to the northwest at $<1^{\circ}$, which is partly due to the planetary pole-to-pole slope and long-wavelength topography imparted by the construction of the Tharsis bulge (Hynek and Phillips, 2008). The map region is a unique place on Mars, along the boundary of the typical southern cratered highlands, and the degraded terrain of Arabia Terra to the north and east, which is thought to have undergone significant resurfacing in the Late Noachian (Hynek and Phillips, 2001). The Arabia Terra region was originally considered typical of cratered highlands (Scott and Tanaka, 1986; Greeley and Guest, 1987), but more recent data have shown that the topography and crustal thickness values are lower (Zuber, 2001) and fluvial dissection is significantly less dense than typical of highland terrains (Hynek and Phillips, 2001). Indeed, it is a transitional terrain, with an elevation, crustal thickness, and character distinct from both the northern lowlands and the southern highlands (Andrews-Hanna and others, 2008). West of the map region elevation decreases, owing to the effects of the emplacement of the Tharsis Montes and a surrounding flexural trough (Phillips and others, 2001). Outflow channel activity was concentrated in this trough, resulting in a prevalence of chaotic terrains (Phillips and others, 2001). The Meridiani Planum region contains strong contrasts in albedo, known since early telescopic observations (Sinton and Strong, 1960), and some of the brightest and darkest terrains of Mars, which are marked by sharp boundaries (Woronow and King, 1972; Presley and Arvidson, 1988).

In the past decade of Mars exploration, numerous outcrops of layered rock and sediment located within Meridiani Planum have been identified (for example, Edgett, 2005), with a total thickness of $\sim 1 \mathrm{~km}$ of layered materials lying unconformably on the older, cratered Noachian crust (for example, Hynek and Phillips, 2008). Data from Mars Global Surveyor's Thermal Emission Spectrometer (TES) instrument identified crystalline gray hematite, which corresponds to a low albedo plains unit that covers $\sim 9 \times 10^{4} \mathrm{~km}^{2}$ and was originally interpreted to have formed through aqueous processes, potentially in an ancient lacustrine environment (Christensen and others, 2000, 2001a). This discovery prompted the selection of Meridiani Planum as a landing site for one of the two MERs (Golombek and others, 2005). The MER Opportunity confirmed hematite in the form of small (millimeter-sized) concretions that were concentrated on the surface, presumably as a lag deposit from the erosion of overlying materials (Squyres and others, 2004; Hynek, 2004). In places, the iron-rich concretions have subsequently been concentrated by the wind into ripples and dunes (for example, Squyres and others, 2004). The underlying geologic units also record a history of water-driven processes and have been altered into abundant Fe-, Mg-, and Ca-sulfates (for example Squyres and others, 2004, 2009; Squyres and Knoll, 2005). In fact, bedrock outcrops examined by MER Opportunity have as much as 25 weight percent sulfur, and the amount varies through the stratigraphic sections with $\mathrm{Mg}$, implying $\mathrm{Mg}$-sulfates locally (Rieder and others, 2004). Crystal voids were also seen with the microscopic imager onboard MER Opportunity and suggest $\mathrm{Fe}$ - and Ca-sulfates as well (Squyres and Knoll, 2005). These units cover more than $2 \times 10^{5} \mathrm{~km}^{2}$ and extend beyond the hematite-bearing plains (Hynek, 2004; Hynek and Phillips, 2008). As a result, the suite of geologic processes that emplaced and subsequently modified the layered units of Meridiani were likely to have operated on a regional scale. This geologic map is intended to delineate the full extent of the layered bedrock, characterize the diverse materials in terms of their properties and ages, place the results of the MER Opportunity in a broader context, and detail the history of water in the region.

Layered rocks and sediments were recognized in Meridiani Planum beginning in the late 1970s, and numerous mechanisms for their origin were proposed based on Viking mission images and thermal data. Scott and Tanaka (1986) and Presley and Arvidson (1988) described the materials as friable sediments that likely consisted of eolian deposits decoupled from the underlying bedrock. Schultz and Lutz (1988) argued that layered units were part of a global set of antipodal, equatorial layered materials that were ancient polar deposits, indicative of true polar wandering in the past. Edgett and Parker (1997) hypothesized that the Meridiani Planum units accumulated as sediments in an ancient subaqueous environment, possibly in a continental shelf setting under an ancient ocean. Post-Viking orbiting and landed spacecraft data led to more detailed studies of the Meridiani Planum geologic units and their temporal relations. The analysis of MGS Mars Orbiter Camera (MOC) data led Malin and Edgett (2001a) and Edgett (2005) to suggest that the regional materials are not sediment mantles, but rather rocky outcrops of the ancient Martian crust. Hynek and others (2002) mapped the regional geology of Meridiani using post-Viking Orbiter data at 1:1,000,000 scale, concluding that the hematite-bearing Meridiani unit was one of several 
easily-erodible plains units (previously identified as "etched" and "subdued" units; Scott and Tanaka, 1986; Greeley and Guest, 1987) that regionally buried the Noachian cratered highlands. These workers also noted morphologic similarity between the "etched" units of Meridiani and terrestrial pyroclastic materials, inferring possible volcanic processes in the region during the Late Noachian to Early Hesperian.

MER Opportunity landed in the western region of the hematite-bearing plains unit in 2004 and detailed the geologic characteristics of the region through more than $20 \mathrm{~km}$ of traverse (Squyres and others, 2009). During that time, MER Opportunity identified stratigraphic relations within a nearly $10-\mathrm{m}$ vertical section of poorly indurated rock and sediment, and observed inaccessible outcrops exposed in crater walls (for example, Squyres and Knoll, 2005; Squyres and others, 2009). MER Opportunity also identified gray hematite spherules on the surface and eroding out of bedrock exposures. These observations led Squyres and others (2004) and Squyres and Knoll (2005), among others, to hypothesize that the Fe-bearing spherules were concentrated on the surface as a lag deposit in sufficient quantities to explain the TES-based observations of gray crystalline hematite in this region of Mars (Christensen and others, 2000, 2001a). Numerous sulfate minerals have been identified in the bedrocks, including jarosite $\left(\mathrm{KFe}_{3}^{3+}(\mathrm{OH})_{6}\left(\mathrm{SO}_{4}\right)_{2}\right), \mathrm{Mg}$-sulfates, and Ca-sulfates (gypsum) (Klingelhöfer and others 2004; Clark and others, 2005; Squyres and Knoll, 2005; Squyres and others, 2009). The mineral jarosite, which is a hydrous iron sulfate, is of particular importance because it forms on Earth in low $\mathrm{pH}$, oxidizing conditions, providing reconstruction of aqueous paleoconditions (Squyres and Knoll, 2005). Finally, clay-bearing minerals, possibly including kaolinite, allophone, and amorphous silica have been noted, which also allude to significant water-bedrock interactions (Clark and others, 2005). McCollom and Hynek (2005) used chemical arguments and models to show that the altered bedrock was originally basaltic in composition, as the elemental chemistry matched well with Mars meteorite samples and MER-based observations of the pristine crustal rocks.

Data from space-borne spectral instruments have helped to reveal the mineralogy of the layered bedrock beyond the hematite deposit, including data from the Observatoire pour la Mineralogie l'Eau, les Glaces et l'Activite (OMEGA) visible to near-infrared spectrometer (Arvidson and others, 2005; Poulet and others, 2008) onboard the European Space Agency's (ESA) Mars Express (MEX) orbiter. These workers identified Mg-sulfates (kieserite and a poly-hydrated Mg-sulfate) stratigraphically below the hematite-bearing plains. More recently, the Compact Reconnaissance Imaging Spectrometer for Mars (CRISM) on the Mars Reconnaissance Orbiter (MRO) has mapped the mineralogy from orbit at a finer spatial scale with targeted observations (Murchie and others, 2007). These data have further detailed the occurrences of sulfates in the layered bedrock (Wray and others, 2009) and phyllosilicate detections in crater rim material led to directed observations by MER Opportunity at these locations (Arvidson, 2016). Hynek and Phillips (2008) used MGS and Mars Odyssey data to complete the first detailed stratigraphic analysis of the layered units of Meridiani Planum. They found that the units conform to the underlying regional slope and are consistent with a regional, low-energy depositional environment during the Late Noachian to Early Hesperian, post-dating most fluvial activity in the region (Hynek and Phillips, 2008). However, surface water still persisted in local lakes after this time period (Hynek and others, 2015).

The new data have spawned new models for emplacement and aqueous alteration of the layered rocks and sediments in Meridiani Planum. Squyres and Knoll (2005) proposed a "dirty evaporite" model, which postulated that eolian-derived sediments were cemented in place by sulfates precipitated by a fluctuating acidic groundwater table that occasionally breached the ground surface. McCollom and Hynek (2005) speculated that the mineralogies observed in the layered rocks and sediments of Meridiani Planum formed as the result of direct acid-sulfate alteration of basaltic ash in a volcanic setting. Knauth and others (2005) suggested that the layered deposits were emplaced (and subsequently altered) by surge deposits related to bolide impacts into a brine-rich substrate. Niles and Michalski (2009) hypothesized that the layered sulfate-rich bedrock was a cemented lag deposit left over from a large accumulation of ice, roughly equivalent to the modern Martian polar caps. Understanding the broader context of the rover results can be accomplished by detailed mapping, and that approach is implemented here to help discriminate between the widely varying hypotheses and timing of geological activity.

The Meridiani Planum region is one of the most mineralogically diverse regions of Mars identified to date, and it records a long history of interaction of water with the Martian crust. Many ideas have been put forth to explain both the voluminous deposits and their aqueous alteration history. Detailed geologic mapping is essential to reveal geologic processes that controlled not only the emplacement of the layered rocks and sediments of Meridiani Planum, but also their subsequent physical and chemical alteration. These efforts can help constrain the duration of water-related geologic processes within this region of Mars and can place the results of the MER Opportunity in a broader geologic, stratigraphic, and structural framework. Although Hynek and others (2002) mapped the Meridiani region at a finer 1:1,000,000-scale, Viking data were the only complete basemap available at the time and the effort was supplemented by incoming data from the Mars Global Surveyor. In contrast, this geologic map was drafted with ample newer, higher spatial resolution data products described below with improved accuracy and precision. Additionally, the new mapping effort expanded the geographic boundaries from Hynek and others (2002) to encompass the full extent of the terrains of interest.

\section{Data}

The primary base map was a $100 \mathrm{~m} /$ pixel Thermal Emission Imaging System (THEMIS) daytime infrared mosaic (Christensen and others, 2001b; fig. 1). Viking images from the Mars Digital Image Mosaic (v. 2.1) were used to fill areas where THEMIS images were not available 
( $<10$ percent of the coverage). The MGS-based Mars Orbiter Laser Altimeter (MOLA) gridded topographic data product (463 m/pixel; Smith and others, 2001) supplemented the Mars Odyssey-based THEMIS base map (fig. 2). In addition to these products, many other Mars datasets were clipped and co-registered in a geographic information system (GIS), including (1) the MGS-based Thermal Emission Spectrometer (TES) nighttime thermal inertia product ( $3 \mathrm{~km} /$ pixel) (Putzig and others, 2005), (2) the TES albedo map $(3 \times 6 \mathrm{~km} /$ pixel $)$ (Christensen and others, 2001b), (3) the TES mineral maps (particularly the hematite map) (Bandfield, 2002), (4) MGSbased Mars Orbiter Camera (MOC) wide- and narrow-angle images $(256 \mathrm{~m} /$ pixel and $\sim 2-10 \mathrm{~m} /$ pixel, respectively; Malin and Edgett, 2001b), (5) Mars Odyssey-based THEMIS band 9-derived (12.57 microns) nighttime thermal inertia map (Hynek, 2004; fig. 3), (6) all available THEMIS visible (VIS) images (18 m/pixel) (Christensen and others, 2001b), (7) Mars Express (MEX) High Resolution Stereo Camera (HRSC) multicolor mosaics ( $20 \mathrm{~m} / \mathrm{pixel})$ (Neukum and others, 2004a) and stereo-derived high-resolution topography ( $\sim 75 \mathrm{~m} /$ pixel), (8) MEX OMEGA instrument with hundreds to 2,000 m/pixel spatial resolution and 0.35-5.1 micron range hyperspectral mapping (Bibring and others, 2005), (9) MRO-based High Resolution Imaging Science Experiment (HiRISE) $(\sim 1 \mathrm{~m} /$ pixel) images (McEwen and others, 2007), (10) MRO Context Camera (CTX) images ( $\sim 6 \mathrm{~m} /$ pixel) (Malin and others, 2007), and (11) mineral maps derived from the MRO-based Compact Reconnaissance Imaging Spectrometer for Mars (CRISM) (15-19 m/pixel) (Murchie and others, 2007).

\section{Mapping Methods}

The linework of unit contacts, structures, and surficial features was digitally streamed into a GIS. The geomorphologically based interpretation of the study area's geology was primarily supplemented by a THEMIS infrared image mosaic basemap and MOLA topography, and also by thermophysical data that provided additional information about the composition at the surface. High-resolution images (for example, MOC, HiRISE, and CTX) were consulted in cases where contacts where unclear at THEMIS scale. A combination of different criteria, including textural, morphological, topographic, and thermophysical properties, was used to differentiate the map units. The units were named based on primary morphologic criteria (for example, plains unit) as well as unconformities and other map relationships. Closely related units were also distinguished based on their stratigraphic position. For example, the Meridiani Planum etched units $\left(\mathrm{NMe}_{1}, \mathrm{NMe}_{2}, \mathrm{HNMe}_{3}\right.$, and $\left.\mathrm{HNMe}_{\mathrm{u}}\right)$ could have been mapped as a single unit based on their overall characteristics, but were subdivided into lower $\left(\mathrm{NMe}_{1}\right)$, middle $\left(\mathrm{NMe}_{2}\right)$, upper $\left(\mathrm{HNMe}_{3}\right)$, and undivided $\left(\mathrm{HNMe}_{4}\right)$ units based on their elevation throughout the map area, distinct morphologies, and stratigraphic position.

Mapped units were grouped primarily by their geographic occurrence in three main classes: Meridiani Planum units, plains units, and highlands units. The highlands units are representative of typical southern highland cratered terrains (Scott and Tanaka, 1986). The Meridiani Planum units contain layered deposits that are unconformably superposed on the highlands units. The plains units mostly post-date formation of the Meridiani Planum units and occur beyond these boundaries. The first letter of the unit symbols indicates chronostratigraphic age when confidently defined (for example, $\mathrm{N}$ for Noachian, $\mathrm{H}$ for Hesperian). Unit symbols also include formal and informal physiographic group designations ("p" for plains, "M" for Meridiani Planum, "h" for highland, and "c" for crater). Additionally, unit symbols contain specific morphological designations (for example, "e" for the etched units).

Unit colors were chosen to be similar to those on previously published Mars geological maps (where possible) and to reflect their stratigraphic grouping. For example, we used shades of brown for ancient highland materials $\left(\mathrm{Nhc}_{1}\right.$ and $\mathrm{Nhc}_{2}$ ) and blue for a unit most likely related to hydrologic activity (Hpct). A range of pink to violet shades were used for the etched units $\left(\mathrm{NMe}_{1}, \mathrm{NMe}_{2}, \mathrm{HNMe}_{3}\right.$, and $\left.\mathrm{HNMe}_{\mathrm{u}}\right)$ to highlight these key units.

The spatial accuracy and degree of confidence in identifying unit contacts were extremely variable throughout the map area due to the quality and availability of data, reduced contrast of surface character as a result of differing degrees of preservation, and (or) the overall continuity and stratigraphic relations of units. We employed precise definitions for describing the overall quality and reliability of the defined contacts (certain versus approximate) and consistently used the specific contact types formalized in the Planetary Geologic Mappers Handbook by Tanaka and others (2010). Herein, we used a certain contact to indicate that the contact is clearly observed and confidently located, and an approximate contact to indicate that the contact is not clearly observed (for example, is inferred) and (or) is not confidently located (for example, is gradational).

Several feature types were also defined and mapped throughout the region. Linear symbols included topographic features such as crests of exposed or buried crater rims, yardangs, wrinkle ridges, sinuous ridges, narrow grabens, depressions, dome margins, and troughs. Linear features were mapped if their length was greater than $\sim 8 \mathrm{~km}$ in length. Overly dense regions of structures (such as in the chaotic terrains) were locally generalized for clarity. Wrinkle ridges were divided into "certain" and "approximate", in regard to their interpretive and (or) locational positional confidence. Surficial feature mapping includes a stipple pattern indicating secondary crater chains and hachure patterns showing the major areas covered by continuous patches of low and high albedo wind-derived mantle observed in visible wavelengths. Large regions composed of spatially expansive, integrated fluvial valleys were noted as surficial features (valley surfaces) whereas sporadic individual valleys were mapped as linear features (valleys).

Based on map scale $(1: 2,000,000)$, linework was digitized at 1:400,000 scale, with an average vertex spacing of $600 \mathrm{~m}$, and exported in ESRI shapefile format using a Mercator projection centered at long $0^{\circ} \mathrm{E}$. and the Mars 2000 sphere 
(with radius $=3,396,190 \mathrm{~m}$ ) reference system (Seidelmann and others, 2002). Individual outcrops were mapped if they were at least $11 \mathrm{~km}^{2}$. Finally, craters were mapped as undivided units when less than $20 \mathrm{~km}$ wide, including the ejecta blankets. To avoid topological errors and preserve the original shape of the outlined contacts, smoothing operations were only minimally performed on the final GIS linework.

\section{Age Determinations}

We determined ages of map units according to their stratigraphic relations (superposition and cross-cutting) and also from crater counting techniques (both relative chronostratigraphic and absolute model ages). The absolute model ages crater-counting statistics are summarized in table 1 and helped us constrain the stratigraphic inferences and geologic interpretations, as well as provided a quantitative approach for reconstructing the geology of the region. Numbers of craters and crater size-frequency distributions have been derived for each map unit using craters extracted from a global database of Martian impact craters compiled down to the size of 1.0-km-diameter (Robbins and Hynek, 2012). Meridiani Planum etched units $\left(\mathrm{NMe}_{1}, \mathrm{NMe}_{2}, \mathrm{HNMe}_{3}\right.$, and $\left.\mathrm{HNMe}_{4}\right)$ were considered as a single unit for crater counting purposes because they are stratigraphically linked and individual members are locally difficult to distinguish (for example, unit $\mathrm{HNMe}_{\mathrm{u}}$ ).

Relative ages were calculated from the number of craters $\geq 2 \mathrm{~km}, \geq 5 \mathrm{~km}$, and $\geq 16 \mathrm{~km}$ in diameter, normalized to a reference surface of $10^{6} \mathrm{~km}^{2}$ (see table 1), and based on the standard chronostratigraphic boundaries defined by Tanaka (1986). Error values and uncertainties were calculated assuming a Poisson distribution, allowing $1 \sigma$ to be estimated as $\mathrm{N}= \pm(\mathrm{N})^{1 / 2}$, where $\mathrm{N}$ is the number of craters (Arvidson and others, 1979). Particularly, we corroborated the inferred geometric relations between the mapped units, making assumptions on their chronostratigraphic ages (see table 1 and the Correlation of Map Units), by referring to the $\mathrm{N}(5)$ and $\mathrm{N}(16)$ system (Tanaka, 1986). We preferred to indicate possible ages using a combination of the $\mathrm{N}(5)$ and $\mathrm{N}(16)$ reference systems as the former was more indicative for units with smaller areal extents and with an insignificant (from a statistical point of view) number of craters $>16 \mathrm{~km}$ in diameter (for example, units Hpct and HMh). The N(16) value was considered more reliable for the units with larger areal extents and overall for the oldest units cropping out throughout the map area (for example, units $\mathrm{Nhc}_{1}$ and $\mathrm{Nhc}_{2}$ ). $\mathrm{N}(1)$ values were ignored for this work because abundant resurfacing and secondary craters in the region lead to spurious age determinations.

In addition to the chronostratigraphic ages, we also determined possible absolute model ages for key map units (see table 1 and fig. $5 A-F$ ). Crater size-frequency distribution plots were determined using the Craterstats tool (Michael and Neukum, 2007). We used the cratering chronology of Hartmann and Neukum (2001) and the crater production function and polynomial coefficients of Ivanov (2001). Absolute model age determinations for Mars are obtained from the lunar crater production curve and the cratering chronology model using
Martian crater scaling laws (Soderblom and others, 1974; Neukum and Wise, 1976; Hartmann, 1977; Neukum and Hiller, 1981; Ivanov, 2001; Stöffler and Ryder, 2001). The combined errors result in an uncertainty of the derived absolute model ages of 20-30 percent for ages $<3 \mathrm{Ga}$ and an uncertainty of only 100-200 Ma for ages $>3 \mathrm{Ga}$ (Neukum and others, 2004b), although ages $<3$ Ga may be affected by a systematic error in the crater frequency (Hartmann and Neukum, 2001; Ivanov, 2001). Absolute model age determinations could also be biased owing to the importance of secondary craters (for example, small craters formed by the material ejected after the formation of a larger crater) in the overall record of craters and especially for diameters $<500 \mathrm{~m}$ (McEwen and others, 2005; Hartmann, 2005). Thus, all map units for which crater counts were performed were carefully mapped and obvious cluster fields of small craters, possibly indicating secondary crater chains, were not considered during the counting operations (for example, see the northeastern corner of the map for secondary crater chains radially emanating from a large crater [mapped as unit $\mathrm{C}_{2}$ ] centered at approximately lat $11.4^{\circ} \mathrm{N}$ and long $13.6^{\circ} \mathrm{E}$.). Moreover, partly to avoid the problem of the secondary craters, and partly to enable a direct comparison between the absolute model ages and the previously discussed chronostratigraphic ages, the derived crater size-frequency plots (fig. 5) for the map units were based on craters with diameter $>1.0 \mathrm{~km}$, whereas the best fit absolute model ages (table 1 and fig. 5) were calculated by considering only craters with diameter $>5 \mathrm{~km}$.

In general, the results from crater statistics support the chronology and evolution determined from stratigraphic relations and geologic interpretations from the mapping (see table 1 and the Correlation of Map Units). Particularly, both chronostratigraphic and absolute model ages for the old units throughout the map area $\left(\mathrm{Nhc}_{1}\right.$ and $\mathrm{Nhc}_{2}$ ) are broadly in agreement and range from the Early to Late Noachian Epoch. However, distinctions should be made according to the overall resurfacing history of each unit. Unless indicated by the (s) suffix following the unit's name (table 1), statistics and associated age determinations were obtained using the total crater counts for each unit. The latter approach is reasonable and does not affect the results for old units (for example, units $\mathrm{Nhc}_{1}$ and $\mathrm{Nhc}_{2}$ ), but it can lead to an overestimate for the age of younger units (for example, units $\mathrm{Hp}, \mathrm{HMh}$, and Hpct).

Therefore, additional crater counts using only the population of relatively fresh craters superimposed on the unit were performed for unit HMh (because the majority of craters within this unit are buried or subdued), unit $\mathrm{Hp}$ (because this is a unit that embays low-lying units), and unit Hpct (because chaotic terrains form after the emplacement of the hosting craters). The superimposed crater approach was also attempted for the Meridiani Planum etched units $\left(\mathrm{NMe}_{1}, \mathrm{NMe}_{2}, \mathrm{HNMe}_{3}\right.$, and $\left.\mathrm{HNMe}_{4}\right)$. However, in the latter cases, superimposed counts were statistically invalid due to the small number of fresh craters. The time designations of these units are approximate and bounded by their superposition over the cratered units $\left(\mathrm{Nhc}_{1}\right.$ and $\mathrm{Nhc}_{2}$ ) and embayment by younger units (Hpct and usually $\mathrm{Hp}$ ).

A comparison of the results (see table 1 and plots in fig. $5 E-F$ ) between the total versus superimposed crater 
population show that the HMh unit would have approximately the same age $(3.90 \mathrm{Ga})$ as the underlying etched units $(3.88 \mathrm{Ga})$ when considering all of the craters, but when using only superimposed craters the unit would be about 400 million years younger $(3.55 \mathrm{Ga})$. Moreover, the resurfacing of this unit is also shown by the downturn at small diameters in the crater size-frequency distribution plot in figure $5 E$. The $\mathrm{Hp}$ unit (see table 1 and plot in fig. $5 D$ ) would have approximately the same age $(3.86 \mathrm{Ga})$ as the underlying $\mathrm{Nhc}_{1}$ and $\mathrm{Nhc}_{2}$ units $(3.92 \mathrm{Ga})$ when considering all of the craters, but when using only superimposed craters the unit would be about 200 million years younger $(3.66 \mathrm{Ga})$, in better agreement with the inferred stratigraphic relations and geologic interpretations. Moreover, the $\mathrm{Hp}$ unit formed over various and extended time periods in regions of the mapped area. Thus, although the average age of unit emplacement is $3.66 \mathrm{Ga}$, in some areas the unit was emplaced in younger epochs and overlapping with formation of unit Hpct in the Late Hesperian and this is represented in the Correlation of Map Units (sheet 1). Unit HMh exhibits an absolute model age of $3.55 \mathrm{Ga}$ (Late Hesperian) when considering the superimposed crater population. However, stratigraphic relations suggest the unit was emplaced just after unit $\mathrm{HNMe}_{3}$, and detailed examination of unit HMh shows a long history of eolian resurfacing processes that we infer has obliterated craters, giving it an inaccurate young absolute model age from crater statistics. Unit Hpct has a calculated absolute model age that is much older than the stratigraphic relations imply. We attribute this discrepancy to small number statistics and a lack of obliteration of some pre-existing craters as the unit formed.

\section{Geologic History}

Based on the stratigraphic inferences, geologic observations, and constraints from crater counting techniques, the geologic history of the map region can be ideally reconstructed as follows. During the Early Noachian Epoch, the heavy bombardment period in the history of Mars (Chapman and Jones, 1977), the region was likely affected by large and spatially extensive impact processes, whose signs are still preserved in the uplifted crustal materials found around the rims of large impact craters (for example, Schiaparelli crater, southeastern part of the map). This activity resulted in the formation of the oldest preserved crust in the region. Impacts continued throughout the Noachian, although their size and frequency generally decreased through time (Hartmann and Neukum, 2001). The Tharsis load was likely emplaced during the Noachian, warping the long-wavelength topography of the planet (Phillips and others, 2001). Locally, this resulted in regional tilting of the Meridiani region to the northwest at less than one degree slope (Phillips and other, 2001), owing to the effects of Tharsis and the existing pole-to-pole slope, which is one of the oldest known features on Mars (Solomon and others, 2005).

The impacts resulted in the formation of the cratered and subdued cratered units ( $\mathrm{Nhc}_{1}$ and $\mathrm{Nhc}_{2}$, respectively). These units are analogous to units $\mathrm{Npl}_{1} / \mathrm{Npld}$ and $\mathrm{Npl}_{2}$, respectively, as described by Scott and Tanaka (1986) and Greeley and Guest (1987). These cratered units are interpreted as essentially the same material - a mixture of volcanic deposits (both lava and pyroclastic flows), impact breccias, impact-related melt sheets, and erosional deposits. The antiquity of these units precludes precise geological interpretations, but given their size and the dynamic early history of Mars, multiple cratering and volcanic processes were likely active. A significant number of wrinkle ridges are found in association with these units, suggesting the occurrence of contractional tectonic activity following formation. However, the $\mathrm{Nhc}_{1}$ unit also shows evidence of erosional features and deposits produced by fluvio-lacustrine processes, such as significant development of mature valley networks, infilling of crater floors, and degradation of crater rims. The latter processes mostly modified the cratered surface in the southern part of the map area and emplaced intercrater and intracrater plains. The fluvio-lacustrine processes led to a propensity of heavily degraded craters (unit $\mathrm{c}_{1}$ ) on unit $\mathrm{Nhc}_{1}$, while unit $\mathrm{Nhc}_{2}$ exhibits a relatively higher abundance of moderately-degraded craters (unit $\mathrm{C}_{2}$ ) due to the more moderate degree of resurfacing experienced by this unit. Some of the sediments were deposited by way of fluvio-lacustrine and mass wasting processes within the existing craters, leading to layered intracrater plains mapped as internal crater deposits (unit ci). An evolutionary path from crater fill (unit cf) to unit ci is inferred, with the latter having experienced more intense and (or) prolonged modification. These deposits are generally confined to the highlands units because those are interpreted to have undergone the most intense fluvial erosion after emplacement. Well-integrated catchments with as much as the sixth-order level of tributaries are incised into unit $\mathrm{Nhc}_{1}$, indicating that it is older and more degraded than unit $\mathrm{Nhc}_{2}$. The timing of this activity is also broadly confirmed by quantitative crater-age determinations in the valley networks themselves, placing the end of the hydrological activity in this area around the Late Noachian-Early Hesperian (Hoke and Hynek, 2009).

Meridiani Planum etched units $\left(\mathrm{NMe}_{1}, \mathrm{NMe}_{2}, \mathrm{HNMe}_{3}\right.$, and $\mathrm{HNMe}_{\mathrm{u}}$ ) were emplaced unconformably on top of units $\mathrm{Nhc}_{1}$ and $\mathrm{Nhc}_{2}$ from the Late Noachian to the Early Hesperian, as observed in all contact relations between the units. This is evidenced by the observation that the etched units bury, in places, the mouths of the drainage systems, which were active until the Early Hesperian. In other words, the valley networks do not generally cut through the etched units, suggesting a later emplacement of these terrains with respect to the hydrological activity that incised the cratered unit $\mathrm{Nhc}_{1}$. These units are composed of friable layered deposits that conform to the underlying long-wavelength topography. The divisions between units $\mathrm{NMe}_{1}$ to $\mathrm{HNMe}_{3}$ are based on widely occurring and sharp stratigraphic marker beds that can be continuously mapped for more than $600 \mathrm{~km}$ in places (Hynek and Phillips, 2008). The origin of the etched units, however, is still unclear. Several hypotheses have been put forth to explain the deposition of these highly erodible materials. These alternatives include eolian, lacustrine, groundwater, ice-related, and (or) volcanic depositional processes (Squyres and Knoll, 2005; McCollom and Hynek, 2005; Knauth and others, 2005; Niles and 
Michalski, 2009). Any hypothesis must explain a large scale, low-energy depositional process that follows the pre-existing surface slope and does not require a closed basin. From these stratigraphic criteria, Hynek and Phillips (2008) concluded that a fluctuating groundwater table in an eolian environment or deposition of pyroclastic ash were the most likely candidates. An abundance of outliers of these materials throughout the central part of the map region, including within impact craters, suggests that the deposits could have had a larger and more contiguous extent over the region in the past. Therefore, whichever processes were responsible for the emplacement and modification of these units must have operated at regional scale and likely for a significant amount of time. In the case of cementation of eolian sediments by a fluctuating groundwater table (Squyres and Knoll, 2005), the implication is that there was a regional-scale aquifer near the surface of Mars over most of the region (Andrews-Hanna and others, 2007). In the volcanic ash scenario (McCollom and Hynek, 2005), an equally large process would have been needed to account for the extent and thickness of these units.

There are numerous layered mounds within the interiors of impact craters, mainly outside of the boundaries of the Meridiani Planum etched units. These mounds share many morphological characteristics with the etched units, including high albedo, near-flat layers that have been heavily eroded by eolian processes to produce etched textures and abundant linear ridges interpreted herein as yardangs. Based mainly on morphology and partly on crater counts, these units likely have the same age and formational mechanism as that of the adjacent Meridiani Planum etched units. Because these outcrops were not directly linkable to the individual members of the Meridiani Planum etched units, they were grouped with the etched units and designated as unit $\mathrm{HNMe}_{\mathrm{u}}$. Subsequent to formation, these crater mounds were affected by intense eolian erosion and lineaments interpreted as yardangs, which is a common secondary characteristic of this unit. In fact, the thinly layered and friable nature of unit $\mathrm{HNMe}_{u}$ supports the notion that these are erosional outliers of the Meridiani Planum etched units. Therefore, the etched units likely had a larger and more contiguous extent over the map region, and currently outcrop only within impact craters, possibly because there they are thicker and more protected from deflation and (or) the basin setting contributed to enhanced cementation in these locales.

Stratigraphic and mapping relations suggest that the flat, dark, and thin character of unit HMh likely occurred during the Early Hesperian. As seen from MER Opportunity images, this unit is composed of iron-rich spherules concentrated as a lag deposit and modified by eolian processes into dunes and ripples (Squyres and others, 2004). The unit is exclusively associated with the Meridiani Planum etched units. In fact, its outcrops represent smooth surfaces directly overlying only unit $\mathrm{HNMe}_{3}$. Additional, irregularly shaped patches of unit HMh are scattered close to the largest, contiguous occurrence of that unit. In all cases, unit HMh superposes the Meridiani Planum etched units. At least at the MER Opportunity landing site, unit HMh is a lag deposit of iron-bearing spherules that sufficiently obscures most of the underlying etched bedrock. This interpretation has been extended throughout Meridiani Planum based on orbiter observations (Hynek, 2004). The spherules likely formed from precipitation of iron-rich fluids on nucleation sites within the bedrock (Squyres and Knoll, 2005). Over time, the spherules were physically weathered out of the uppermost outcrops of unit $\mathrm{HNMe}_{3}$ unit and then concentrated on the surface as a lag deposit, which armored further removal of unit $\mathrm{HNMe}_{3}$. Also in this case, the occurrence of isolated patches around the main extensive outcrop suggests that the deposits could have had a larger and more contiguous extent over the region.

Almost contemporaneous with unit HMh, unit Hp likely started to be emplaced around the Early Hesperian in the low-lying plains located in the central part of the map region. In all cases, mapping relations show unit $\mathrm{Hp}$ embaying both unit HMh and the Meridiani Planum etched units, arguing for its younger age. Unit $\mathrm{Hp}$ embays all of the underlying units $\left(\mathrm{HMh}, \mathrm{HNMe}_{\mathrm{u}}, \mathrm{HNMe}_{3}, \mathrm{NMe}_{1}, \mathrm{Nhc}_{1}\right.$, and $\mathrm{Nhc}_{2}$ ) and forms irregularly shaped outcrops of smooth, areally extensive planar surfaces characterized by long, parallel, linear to sinuous, and (in places) closely spaced, wrinkle ridges. In places, unit $\mathrm{Hp}$ contains lobate margins and other features suggestive of low-viscosity lava flows. Unit Hp was likely sourced from multiple locations and generally overlies all mapped units. However, in the southwest part of the map region, the unit is dissected and disrupted by the chaotic plains unit (Hpct). The sources of volcanic eruption are not evident, but likely originate from buried fracture systems that supplied fluid lava flows. The unit is similar in character and interpretation to the Hesperian ridged plains material (unit Hr) of Scott and Tanaka (1986) and Greeley and Guest (1987). Valley networks occasionally incise unit $\mathrm{Hp}$ in the southern part of the map region, supporting an interpretation that fluvial activity extended into the Early Hesperian in this area (Hynek and others, 2015).

Unit Hpct occurs only in the southwestern part of the map region as an eastern extension of the large chaotic complex of Iani Chaos, located just west of map region. Heavily fractured deposits that fill topographic depressions, including impact craters, are typical of unit Hpct and are similar to other chaotic terrains associated with Martian outflow channels (for example, Rotto and Tanaka, 1995). These workers argued that this unit was likely formed by water-related, tectonic, and (or) volcanic/ hydrothermal processes. However, the hydrologic activity seems unrelated to the processes responsible for the formation of unit $\mathrm{Nhc}_{1}$ in the southern part of the map region given the distinct ages and morphologies. Unit Hpct is the youngest unit mapped within the region based on cross-cutting and stratigraphic relations. In fact, it cuts through unit $\mathrm{Hp}$, which represents the second youngest unit of the map. This interpretation is confirmed by previous studies that suggest these chaotic terrains formed from the Early Hesperian to the Early Amazonian (Rotto and Tanaka, 1995; Tanaka, 1997).

All mapped units have been modified from their original surface characteristics through both erosional and depositional processes. These processes have not been uniform. For example, the Meridiani Planum etched terrains $\left(\mathrm{NMe}_{1}, \mathrm{NMe}_{2}\right.$, $\mathrm{HNMe}_{3}$, and $\mathrm{HNMe}_{4}$ ) and unit $\mathrm{HMh}$ contain evidence for the most modification by eolian processes, perhaps alluding to 
inherent mechanical weakness within these units. All units have developed a population of small, pristine impact craters. Unit $\mathrm{C}_{3}$ superposes all larger units and has a random spatial distribution across the map region. The impact craters within this unit all contain well-defined rims and ejecta blankets, and many have interior structures (unit cf - crater fill) related to the crater formation and modification processes. The strong albedo contrasts in the region are attributed to a surficial dust cover (light-toned areas in visible wavelengths) that may not have been derived locally, whereas the visibly dark terrains lack dust from recent or contemporary scouring activity.

\section{Acknowledgments}

We are greatly indebted to Ken Tanaka (USGS), James Skinner (USGS), Corey Fortezzo (USGS), and Rossman Irwin (NASM/CEPS) for their meticulous and constructive reviews, and Katherine Jacques for editing. We also thank Stuart Robbins (SwRI) for his contributions relating to the crater statistics and chronology. This work was supported by NASA's Planetary Geology and Geophysics Program.

\section{References}

Andrews-Hanna, J.C., Phillips, R.J., and Zuber, M.T., 2007, Meridiani Planum and the global hydrology of Mars: Nature, v. 446, p. 163-166, doi:10.1038/nature05594.

Andrews-Hanna, J.C., Zuber, M.T., and Banerdt, W.B., 2008, The Borealis basin and the origin of the martian crustal dichotomy: Nature, v. 453, p. 1212-1215.

Arvidson, R.E., 2016, Aqueous history of Mars as inferred from landed mission measurements of rocks, soils, and water ice: Journal of Geophysical Research, v. 121, p. 1602-1626, doi: 10.1002/2016JE005079.

Arvidson, R.E., Boyce, J.M., Chapman, C.R., and 8 others, 1979, Standard techniques for presentation and analysis of crater size-frequency data: Icarus, v. 37, p. 467-474.

Arvidson, R.E., Poulet, Francois, Bibring, J.-P., and 7 others, 2005, Spectral reflectance and morphologic correlations in eastern Terra Meridiani, Mars: Science, v. 307, p. 1591-1594.

Bandfield, J.L., 2002, Global mineral distributions on Mars: Journal of Geophysical Research, v. 107, p. 9-1-9-20.

Bibring, J-P., Langevin, Yves, Gendrin, Aline, and 9 others, 2005, Mars surface diversity as revealed by the OMEGA/ Mars Express observations: Science, v. 307, p. 1576-1581, doi:10.1126/science.1108806.

Chapman, C.R., and Jones, K.L., 1977, Cratering and obliteration history of Mars: Annual Review of Earth and Planetary Sciences, v. 5, p. 515-540.

Christensen, P.R., Bandfield, J.L., Clark, R.N., and 13 others, 2000, Detection of crystalline hematite mineralization on Mars by the Thermal Emission Spectrometer-Evidence for near-surface water: Journal of Geophysical Research, v. 105, p. 9623-9642.

Christensen, P.R., Bandfield, J.L., Hamilton, V.E., and 23 others, 2001b, Mars Global Surveyor Thermal Emission Spectrometer experiment-Investigation description and surface science results: Journal of Geophysical Research, v. 106, p. $23,823-23,871$.

Christensen, P.R., Morris, R.V., Lane, M.D., and 13 others, 2001a, Global mapping of Martian hematite mineral depositsRemnants of water-driven processes on early Mars: Journal of Geophysical Research, v. 106, p. 23,873-23,886.

Clark, B.C., Morris, R.V., McLennan, S.M., and 21 others, 2005, Chemistry and mineralogy of outcrops at Meridiani Planum: Earth and Planetary Science Letters, v. 240, p. 73-94.

Edgett, K.S., 2005, The sedimentary rocks of Sinus MeridianiFive key observations from data acquired by the Mars Global Surveyor and Mars Odyssey orbiters: Mars, v. 1, p. 5-58, doi:10.1555/mars.2005.0002.

Edgett, K.S., and Parker, T.J., 1997, Water on early MarsPossible subaqueous sedimentary deposits covering ancient cratered terrain in western Arabia and Sinus Meridiani: Geophysical Research Letters, v. 24, p. 2897-2900.

Golombek, M.P., Arvidson, R.E., Bell, J.F., III, and 13 others, 2005, Assessment of Mars Exploration Rover landing site predictions: Nature, v. 436, p. 44-48.

Greeley, Ronald, and Guest, J.E., 1987, Geologic map of the eastern equatorial region of Mars: U.S. Geological Survey Miscellaneous Investigations Series Map, I-1802-B, scale $1: 15,000,000$.

Hartmann, W.K., 1977, Relative crater production rates on planets: Icarus, v. 31, p. 260-276.

Hartmann, W.K., 2005, Martian cratering-Isochron refinement and the chronology of Mars: Icarus, v. 174, p. 294-320, doi:10.1016/j.icarus.2004.11.023.

Hartmann, W.K., and Neukum, Gerhard, 2001, Cratering chronology and the evolution of Mars: Space Science Reviews, v. 96, p. 165-194.

Hoke, M.R.T., and Hynek, B.M., 2009, Roaming zones of precipitation on ancient Mars as recorded in valley networks: Journal of Geophysical Research, v. 114, E08002, doi:10.1029/2008JE003247.

Hynek, B.M., 2004, Extensive bedrock throughout Terra Meridiani, Mars: Implications for hydrologic processes: Nature, v. 431, doi:10.1038/nature02902.

Hynek, B.M., Arvidson, R.E., and Phillips, R.J., 2002, Geologic setting and origin of Terra Meridiani hematite deposit on Mars: Journal of Geophysical Research, v. 107, doi:10.1029/2002JE001891.

Hynek, B.M., Osterloo, M.K., and Young, K.S., 2015, Late stage formation of martian chlorides: Geology, v. 43, no. 9, p. 787-790, doi:10.1130/G36895.1.

Hynek, B.M., and Phillips, R.J., 2001, Evidence for extensive denudation of the Martian highlands: Geology, v. 29, p. 407-410.

Hynek, B.M., and Phillips, R.J., 2008, The stratigraphy of Meridiani Planum, Mars, and implications for the layered deposits' origin: Earth and Planetary Science Letters, v. 274, p. 214-220.

Ivanov, B.A., 2001, Mars/Moon cratering rate ratio estimates: Space Science Reviews, v. 96, p. 87-104. 
Klingelhöfer, Göstar, Morris, R.V., Bernhardt, Bodo, and 16 other authors, 2004, Jarosite and hematite at Meridiani Planum from the Mössbauer spectrometer on the Opportunity rover: Science, v. 306, p. $1740-1745$.

Knauth, L.P., Burt, D.M., and Wohletz, K.H., 2005, Impact origin of sediments at the Opportunity landing site on Mars: Nature, v. 438, p. 1123-1128, doi:10.1038/nature04383.

Malin, M.C., Bell, J.F., III, Cantor, B.A., and 11 others, 2007, Context camera investigation on board the Mars Reconnaissance Orbiter: Journal of Geophysical Research, v. 112, E05S04, doi:10.1029/2006JE002808.

Malin, M.C., and Edgett, K.S., 2001a, Sedimentary rocks of early Mars: Science, v. 290, p. 1927-1937, doi:10.1126/ science.290.5498.1927.

Malin, M.C., and Edgett, K.S., 2001b, Mars Global Surveyor Mars Orbiter Camera-Interplanetary cruise through primary mission: Journal of Geophysical Research, v. 106, p. 23,42923,570, doi:10.1029/2000JE001455.

McCollom, T.M., and Hynek, B.M., 2005, A volcanic environment for bedrock diagenesis at Meridiani Planum on Mars: Nature, v. 438, p. 1129-1131.

McEwen, A.S., Eliason, E.M., Bergstrom, J.W., and 12 others, 2007, Mars Reconnaissance Orbiter's High Resolution Imaging Science Experiment (HiRISE): Journal of Geophysical Research, v. 112, E05S02, doi:10.1029/2005JE002605.

McEwen, A.S., Preblich, B.S., Turtle, E.P., and 6 others, 2005, The rayed crater Zunil and interpretations of small impact craters on Mars: Icarus, v. 176, p. 351-381.

Michael, G.G., and Neukum, Gerhard, 2007, Refinement of cratering model age for the case of partial resurfacing [abs.]: Lunar and Planetary Science Conference XXXVIII, no. 1825.

Murchie, S.L., Arvidson, R.E. Bedini, P.D., and 47 others, 2007, Compact Reconnaissance Imaging Spectrometer for Mars (CRISM) on Mars Reconnaissance Orbiter (MRO): Journal of Geophysical Research, v. 112, E05S03, doi:10.1029/2006JE002682.

Neukum, Gerhard, and Hiller, J.K., 1981, Martian ages: Journal of Geophysical Research, v. 86, p. 3097-3121.

Neukum, Gerhard, Jaumann, Ralf, Hoffmann, Harald, and 9 others, 2004b, Recent and episodic volcanic and glacial activity on Mars revealed by the High Resolution Stereo Camera: Nature, v. 432, p. 971-979.

Neukum, Gerhard, Jaumann, Ralf, and the HRSC Co-Investigator and Experiment Team, 2004a, HRSC-The High Resolution Stereo Camera of Mars Express: European Space Agency Special Publication, ESA SP-1240, p. 17-35.

Neukum, Gerhard, and Wise, D.U., 1976, Mars-A standard crater curve and possible new time scale: Science, v. 194, p. 1381-1387.

Niles, P.B., and Michalski, Joseph, 2009, Meridiani Planum sediments on Mars formed through weathering in massive ice deposits: Nature Geoscience, v. 2, p. 215-220.

Phillips, R.J., Zuber, M.T., Solomon, S.C., and 8 others, 2001, Ancient geodynamics and global-scale hydrology on Mars: Science, v. 291, p. 2587-2591.

Poulet, Francois, Arvidson, R.E., Gomez, C., and 5 others, 2008,
Mineralogy of Terra Meridiani and western Arabia Terra from OMEGA/MEx and implications for their formation: Icarus, v. 195, p. 106-130.

Presley, M.A., and Arvidson, R.E., 1988, Nature and origin of materials exposed in the Oxia Palus -western Arabia -Sinus Meridiani region, Mars: Icarus, v. 75, p. 499-517.

Putzig, N.E., Mellon, M.T., Kretke, K.A., and Arvidson, R.E., 2005, Global thermal inertia and surface properties of Mars from the MGS mapping mission: Icarus, v. 173, p. 325-341, doi:10.1016/j.icarus.2004.08.017.

Rieder, R., Gellert, R., Anderson, R.C., and 12 others, 2004, Chemistry of rocks and soils at Meridiani Planum from the Alpha Particle X-ray Spectrometer: Science, v. 306, no. 5702, p. 1746-1749.

Robbins, S.J., and Hynek, B.M., 2012, A new global database of Mars impact craters $\geq 1 \mathrm{~km}-1$. database creation, properties, and parameters: Journal of Geophysical Research - Planets, v. 117, doi: 10.1029/2011JE003966.

Rotto, Sue, and Tanaka, K.L., 1995, Geologic/geomorphic map of the Chryse Planitia region of Mars: U.S. Geological Survey Miscellaneous Investigations Series, Map I-2441, scale 1:5,000,000.

Schultz, P.H., and Lutz, A.B., 1988, Polar wandering of Mars: Icarus, v. 73, p. 91-141.

Scott, D.H., and Tanaka, K.L., 1986, Geologic map of the western equatorial region of Mars: U.S. Geological Survey Miscellaneous Investigations Series Map, I-1802-A, scale $1: 15,000,000$.

Seidelmann, P.K., Abalakin, V.K., Bursa, Michael, and 8 others, 2002, Report of the IAU/IAG Working Group on Cartographic Coordinates and Rotational Elements of the Planets and Satellites; 2000: Celestial Mechanics and Dynamical Astronomy, v. 82, no. 1, p. 83-111.

Sinton, W.H., and Strong, J., 1960, Radiometric observations of Mars: The Astrophysical Journal, v. 131, p. 459-469.

Smith, D.E., Zuber, M.T., Frey, H.T., and 21 others, 2001, Mars Orbiter Laser Altimeter-Experiment summary after the first year of global mapping of Mars: Journal of Geophysical Research, v. 106, p. 23,689-23,722, doi:10.1029/2000JE001364.

Soderblom, L.A., West, R.A., Herman, B.M., Kreidler, T.J., and Condit, C.D., 1974, Martian planetwide crater distributionsImplications for geologic history and surface processes: Icarus, v. 22, p. 239-263.

Solomon, S.C., Aharonson, Oded, Aurnou, J.M., and 14 others, 2005, New perspectives on ancient Mars: Science, v. 307, no. 5713, p. 1214-1220.

Squyres, S.W., Arvidson, R.E., Bell, J.F., III, and 47 others, 2004, In situ evidence for an ancient aqueous environment at Meridiani Planum, Mars: Science, v. 306, p. 1709-1714.

Squyres, S.W., and Knoll, A.H., 2005, Sedimentary rocks at Meridiani Planum - Origin, diagenesis, and implications for life on Mars: Earth and Planetary Science Letters, v. 240, p. 1-10.

Squyres, S.W., Knoll, A.H., Arvidson, R.E., and 31 others, 2009, Exploration of Victoria Crater by the Mars rover Opportunity: Science: v. 324, p. 1058-1061.

Stöffler, Dieter, and Ryder, Graham, 2001, Stratigraphy and isotope 
ages of lunar geologic units - Chronological standard for the inner solar system: Space Science Reviews, v. 96, p. 9-54.

Tanaka, K.L., 1986, The stratigraphy of Mars: Journal of Geophysical Research, v. 91, E139-E158.

Tanaka, K.L., 1997, Sedimentary history and mass flow structures of Chryse and Acidalia Planitiae: Journal of Geophysical Research, v. 102, no. E2, p. 4131-4150.

Tanaka, K.L., Skinner, J.A, Jr., and Hare, T.M., 2010 Planetary geologic mapping handbook-2010, in Bleamaster, L.F., III, Tanaka, K.L., and Kelley, M.S., eds., Abstracts of the Annual Meeting of Planetary Geologic Mappers, Flagstaff, AZ 2010:
Washington DC, NASA Conference Publication CP-2010217041, appendix, $21 \mathrm{p}$.

Woronow, Alexander, and King, E.A., Jr., 1972, Size frequency distribution of Martian craters and relative age of light and dark terrains: Science, v. 175, p. 755-757.

Wray, J.J., Noe Dobrea, E.Z., Arvidson, R.E., and 5 others, 2009, Phyllosilicates and sulfates at Endeavour Crater, Meridiani Planum, Mars: Geophysical Research Letters, v. 36, doi:10.1029/2009GL040734.

Zuber, M.T., 2001, The crust and mantle of Mars: Nature, v. 412, p. $220-227$.

Table 1. Crater statistics for the map units.

[km, kilometer; Ga, gigaannum (billion years)]

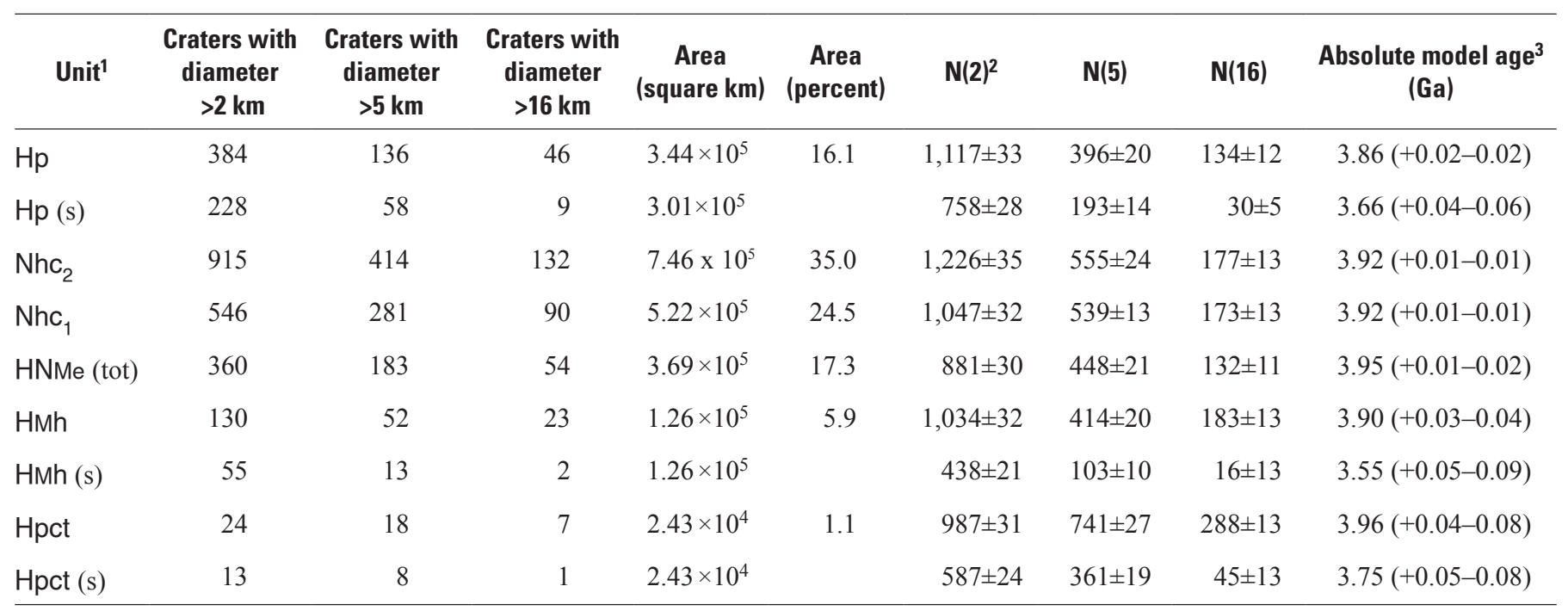

${ }^{1}$ The suffix (s) indicates counts made using only superimposed crater population. The suffix (tot) is used for grouping all etched units together for crater analysis. See text for details.

${ }^{2} \mathrm{~N}(\mathrm{x})$ refers to the number of craters larger than $\mathrm{x} \mathrm{km}$ in diameter per $1 \times 10^{6} \mathrm{~km}^{2}$ (Tanaka, 1986).

${ }^{3}$ Absolute model ages are based on Hartmann and Neukum (2001) with the production functions of Ivanov (2001). 